Review

\title{
Can Adenosine Fight COVID-19 Acute Respiratory Distress Syndrome?
}

\author{
Carmela Falcone 1, t, Massimo Caracciolo 2, t, Pierpaolo Correale ${ }^{3}$, Sebastiano Macheda ${ }^{4}$, Eugenio \\ Giuseppe Vadalà ${ }^{4}$, Stefano La Scala ${ }^{4}$, Marco Tescione ${ }^{4}$, Roberta Danieli ${ }^{5}$, Anna Ferrarelli ${ }^{1}$, Maria \\ Grazia Tarsitano ${ }^{6}$, Lorenzo Romano ${ }^{7, *}$ and Antonino De Lorenzo ${ }^{8}$
}

1 Unit of Radiology, Grande Ospedale Metropolitano Bianchi Melacrino Morelli, Reggio Calabria, 89124, Italy; milafalcone@gmail.com; anferrarelli@yahoo.it;

2 Unit of Intensive Postoperative Therapy, Grande Ospedale Metropolitano Bianchi Melacrino Morelli, Reggio Calabria, 89124, Italy; maxcar04@libero.it;

3 Medical Oncology Unit, Grande Ospedale Metropolitano Bianchi Melacrino Morelli, Reggio Calabria, 89124, Italy; correalep@yahoo.it

4 Unit of Intensive Care Medicine and Anesthesia, Grande Ospedale Metropolitano Bianchi Melacrino Morelli, Reggio Calabria, 89124; nucciomacheda58@gmail.com; eugvad@yahoo.it; stelascala66@gmail.com; marcotescione.mt@gmail.com;

5 Università Telematica San Raffaele, Roma, 00166, Italy; roberta.danieli@uniroma5.it;

6 Department of Experimental Medicine, University of Rome Sapienza, Rome, 00161, Italy; mariagrazia.tarsitano@uniroma1.it;

7 School of Specialization in Food Science, University of Rome Tor Vergata, Rome, 00133, Italy; lorenzo.romano@alumni.uniroma2.eu;

8 Section of Clinical Nutrition and Nutrigenomics, Department of Biomedicine and Prevention, University of Rome Tor Vergata, Rome, 00133, Italy; delorenzo@uniroma2.it

* Correspondence: Correspondence: lorenzo.romano@alumni.uniroma2.eu; (L.R.)

† equal contribution

\begin{abstract}
Some COVID-19 patients develop interstitial pneumonia that can evolve into Acute Respiratory Distress Syndrome (ARDS). This is accompanied by an inflammatory cytokine storm. SarS-CoV has proteins capable of promoting cytokine storm, especially in patients with comorbidities, including obesity.

Since there is currently no resolutive therapy for ARDS and given the scientific literature regarding the use of adenosine, its application has been hypothesized.

Adenosine through its receptors is able to inhibit the acute inflammatory process, increase the protection capacity of the epithelial barrier and reduce the damage due to an overactivation of the immune system, such as in cytokine storms.

These features are known in ischemia / reperfusion models and could also be exploited in acute lung injury, with hypoxia.

In light of these hypotheses, for compassionate use, a COVID-19 patient, with unresponsive respiratory failure, was treated with adenosine.

The results showed a rapid and clear improvement in clinical conditions, with the negative effect of detection of SarS-CoV2.
\end{abstract}

Keywords: COVID-19; ARDS; Adenosine; CT-scan; Cytokines Storm 


\section{Introduction}

COVID-19 outbreak has been declared as pandemic by the WHO reporting more than thirteen million new cases worldwide with 572.539 related deaths [1]. Part of these patients develops interstitial pneumonia that can evolve into Acute Respiratory Distress Syndrome (ARDS). ARDS patients require active hyperoxic ventilation, with mainly fatal outcomes [2]. The pathogenesis of COVID-19related lung injury is still unclear and under study, but the cytokine storm is a severe event with a poor prognosis [2]. For this reason, various drugs have been tested to block the storm, such as the Brut kinase inhibitor [3]. However, therapies such as anti-IL1 $\beta$ (Kanakinumab), IL6 inhibitors (Tocilizumab (TCZ)) and Janus kinase inhibitors (JAK) -1/2 (Baricitinib and Ruxolitinib) have not produced satisfactory clinical outcomes in patients with interstitial pneumonia COVID-19-related [45]. Dramatically, over 50\% of COVID-19 patients needed respiratory support. Studies have shown that some lung complications are due to iatrogenic injury [6]. A previous preclinical study on an animal model [6] observed that oxygenation inhibits the physiological mechanism of protection of the tissues and this could aggravate the ARDS. For this reason, the role of the puraminergic system in preventing respiratory complications in COVID-19 has been investigated. In fact, respiratory support to the COVID-19 patient could contribute to the inhibition of the adenosine pathway mediated by the A2A receptor (A2AR). This pathway involves shutting down the acute inflammatory process in cases of hypoxia.

The following review and clinical case want to clarify the molecular mechanisms involved in the possible use of inhaled adenosine as a therapy to hinder the cytokine storm in COVID-19.

\section{Cytokine storm}

The high mortality in COVID-19 patients has been closely related to the cytokine storm. This is an excessive immune response, with a complex pathogenesis, determining rapid progression and high mortality from the disease [2].

Curiously, numerous patients who quickly died of ARDS did not experience severe symptoms in the early stages of the disease but only the common mild ones.

Cytokine storm is among the causes of ARDS and multi organ failure (MOF) and it is detected in COVID-19 patients [2].

It is clear that in critically ill COVID-19 patients the pathogenesis is promoted by a specific proinflammatory response. In vitro experiments have shown that in the early stage of a Sars-CoV infection, infected cells (respiratory epithelial cells, dendritic cells and macrophages) delay the release of cytokines and chemokines [7-9].

Subsequently, the antiviral factor interferons are secreted at low concentrations, while proinflammatory cytokines (IL-1 $\beta$, IL-6 and Tumor Necrosis Factor (TNF)- $\alpha$ ) and chemokines are widely released [7-9].

In previous coronavirus epidemics, high levels of cytokines and chemokines in infected patients have been observed. In particular, a high number of neutrophils and monocytes in the bloodstream and lungs have been detected [10-13].

At the same time, the delay in interferon secretion results in a reduced and altered antiviral response. Interferons represent the molecular key of the human body defense against viruses infection [14]. Afterwards, the increase in cytokines and chemokines recalls and determines the infiltration of numerous inflammatory cells into the lung. A greater deregulation has already been observed in older primates and other animal models [15].

In Human Coronavirus (hCoV) infection, the ARDS determinants are the delay in the antiviral response, the secretion of cytokines, chemokines, granulocyte-macrophage colony-stimulating factor, reactive oxygen species, chemokines and cell apoptosis products [16]. All this cause apoptosis of the endothelium and pulmonary epithelium, destruction of the respiratory barrier and vascular leakage with alveolar edema. 
A positive correlation between cytokine levels and disease severity was also found in COVID-19 patients, with non-specific recruitment of inflammatory cells. In addition to the pro-inflammatory molecules described so far, COVID-19 patients have also shown the presence of anti-inflammatory cytokines [17].

\section{Mitochondrial dynamism and immune and $\mathrm{hCoV}$ response}

Mitochondria are key organelles of energy metabolism, aging, apoptosis and of the innate immune response [18].

The nature of mitochondria is dynamic and not static. In fact, in order to better preserve its functions, these organelles activate mechanisms of fission, mitophagy and fusion. Those processes are sensitive to cellular physiological and pathological changes and allow a response to stress. Mitochondrial dynamism has a central role in the signaling hub of the innate immune response, effective in contrasting viral pathogenesis [19].

In short, the cyclic and dynamic mitochondrial process eliminates the damaged parts of the mitochondria, recycles the damaged structures and merges mitochondria matters [20].

Fission is coordinated by dynamin-related proteins (DRP), mainly by DRP-1. Following polarization as a result of mitochondrial damage, DRP-1 oligomerizes as a ring and causes the splitting of mitochondrial membranes [21].

Subsequently, the parkin-dependent mitophagy process of the damaged portion of mitochondria is facilitated by selective PTEN-induced kinase 1 (PINK-1) signaling [22].

Finally, the fusion process of the repaired parts takes place thanks to the mito-fusins present on the mitochondrial membrane [23].

Some molecular patterns associated with viruses are recognized by the retinoic acid-inducible gene 1 (RIG-I) and its RIG-I-like Receptors (RLRs) and, by recognizing the double helix RNA, they activate the mitochondrial associated antiviral signaling protein (MAVS) [24]. Mitochondrial fusion and fission activate or attenuate this pathway, with the aim of amplifying the production of interferons and initiating the antiviral immune response. By distorting the mitochondrial dynamism, viruses can prevent the correct production of MAVS [24]. These have a domain within the caspase, caspase recruitment domains (CARDs) and together they promote the activation of the NFkB and the induction of interferon [19].

In addition, the viral strategy in modulating the mitochondrial function provides [19]: impaired calcium regulation; increased oxidative stress; regulation of membrane mitochondrial potential; apoptosis. The hCoV possesses accessory proteins, called Open Reading Frame (ORF), which promote the pathogenesis mechanism. ORF3a and ORF8a trigger the apoptosis; ORF3b promotes the release of different cytokines and chemokines; ORF6 inhibits the production of interferon (INF); and ORF7a promotes transcription mediated by nuclear factor kappa-light-chain-enhancer of activated B cells (NFkB) [18]. Lastly, the role of ORF9b was identified. This protein is responsible for inhibiting MAVS, limiting the innate immune response [25]. In detail, ORF9b promotes the degradation of DRP1 , thus inhibiting mitochondrial fission and MAVS signaling. This process determines cell survival during viral replication [25]. MAVS signaling including the TNF Receptor Associated Factor (TRAF)3/TRAF6 signalosome is downregulated, resulting in decreased INF release and lack of innate immune response [25].

In SarS-CoV-2 several accessory proteins have been identified in common with SarS-CoV [26]. In particular, the same ORF9b sequence as SarS-CoV was detected in a different position of the viral genome [27]. As clinically observed, it would seem that the current virus has all the pathogenetic characteristics to interfere deeply with the innate immune response, to determine a delay in the response, to reduce the production of INF and at the same time to activate the Polymorphonuclear leukocytes (PMN)s response and subsequent cytokine storm.

\section{Adenosine}

Adenosine is a molecule belonging to the oldest signaling systems, probably linked to its biological function [28]. 
This purine has a half-life in vivo of $1.5 \mathrm{~s}$ and is generated by the hydrolysis of polymers. Its messenger activity is carried out in the extracellular space, the purines reach it thanks to transporters, hemichannels, damaged cell membranes or degranulation as adenosine diphosphate (ADP) [29]. In the extracellular space adenosine triphosphate (ATP) and ADP are converted to adenosine monophosphate (AMP) by the exonuclease enzyme cluster of Differentiation (CD) 39. Subsequently, AMP is hydrolyzed into adenosine by the enzyme CD73 [30] the bioavailability of adenosine is limited over time and this is due to the nucleoside transport systems [31], diffusion by gradient, metabolization to Inositol through adenosine deaminase [32] and phosphorylation in AMP via adenosine kinase [33]. In addition, adenosine has 4 receptor subtypes belonging to the G-protein superfamily. Knowledge about the role of adenosine in attenuating and modulating an excessive inflammatory response is emerging. In the experimental ischemia / reperfusion model, adenosine and its agonists have been shown to block infiltration, trafficking, activation of PMNs and the production of superoxides with mitigation of reperfusion damage [34]. By the adenosine signaling, platelets, endothelial cells, macrophages, $\mathrm{T}$ cells and mast cells are also modulated for an antiinflammatory action [35]. Given these properties, adenosine could be used to treat acute lung injury (ALI) and ARDS [36, 37]. In fact, the response of PMNs to adenosine and the presence of receptors for it on the human lung reinforces this hypothesis [38]. In many animal models of ALI and ARDS adenosine or specific agonists have shown the ability to reduce inflammation, regulate endothelial integrity and balance lung fluids [38-40]. Finally, in response to mechanical ventilation an increase in endogenous adenosine production was observed. This response could mitigate lung damage from ventilation [40].

\section{Subtypes of adenosine receptors (AR)}

Subtype A1 is mainly located in the central nervous system and its impact is still poorly understood [38]. It has been observed that its activation is not protective against inflammation, damage from reperfusion and capillary pulmonary filtration [43]. The chronotropic action of adenosine, the slowing of the heart rate, is mediated by subtype A1 [44].

Indeed, efforts have focused on finding a selective antagonist / agonist for this receptor [45].

The A2A subtype is the most common in the human body [46] and its expression is increased in case of damage, especially in macrophages [47]. The cellular responses are different: coronary vasodilation, platelet aggregation inhibition, inhibitory modulation, non-redundant [48], acute immune response against T cells, monocyte, macrophages, PMNs and dendritic cells [49]. The role of A2A in protecting lung integrity from the acute inflammatory process is evident. In fact, the activation determines the suppression of the immune response, the reduction of microvascular permeability and capillary filtration of the lung, preservation of fluid homeostasis, increased clearance of alveolar fluids and inhibition of trans epithelial leukocyte migration $[6,50]$. In acute inflammation, the evaluation of alveolar bronchial lavage has shown that the activation of $\mathrm{A} 2 \mathrm{~A}$ determines a reduction in the secretion of IL-6, TNF- $\alpha$ and chemokine (C-X-C motif) ligand 3 (CXCL1-3) [51].

The A2B subtype is widespread in the body, strongly expressed in the vascular compartment and macrophages, but lowest affinity. It is an effective vasodilator capable of acting in pathological conditions [52]. In addition, it regulates the vessel traffic of leukocytes and has a role in protecting the lung from mechanical ventilation [53]. Its characteristic would help explain the differentiated actions on different cells.

Finally, the subtype A3B is ubiquitous, but specifically located in the lung, liver and eye [46]. Animal models have shown a pro-inflammatory capacity. In humans, only the control of the degranulation of PMNs is clear [54]. Moreover, its activation regulates the production of aqueous humor and selective activation is being tested in dry eye syndrome [55].

\section{Adenosine in the treatment of lung injury}

Currently, adenosine finds its use in the treatment of paroxysmal supraventricular tachycardias, also in the pediatric population [56]. In addition, therapeutic strategies are being studied involving the use of adenosine, and drugs that interact with its metabolism, for the treatment of cancer-mediated 
immunosuppression and other pathologies with a dysregulation of the inflammatory response [5758].

ATP released following an injury performs a diversified signaling function. In fact, its receptors are present in different cells involved in inflammation [60]. In lung damage the role of ATP is controversial. Its action is also expressed in the production of the surfactant and in the regulation of the lung microbiome [60,61].

The exonucleases are central in the anti-inflammatory response, both for the production of adenosine and for the activation of regulatory T cells (T Regs) for CD73 [62]. In lung inflammation, adenosine promotes the cellular response to hypoxia [63], reduction of extravasation of proteins and cytokines in the alveolus with decreased infiltrated neutrophils [64]. A powerful synergy between (peroxisome proliferator-activated receptor $\gamma$ ) PPAR $\gamma$ and adenosine has been observed. They upregulate one another the expression of proteins involved in attenuation of edema, improvement of gas exchange and lung function [65]. Furthermore, adenosine is favored by the presence of CD73 on the T Regs activated through $\mathrm{A} 2 \mathrm{~A}$ and acts as modulator of the immune response and assist in the resolution of the acute phase. [66]. A2A expressed in PMNs reduces its traffic, infiltration and activation, attenuating the inflammatory lung response [64]. As already discussed, most of the antiinflammatory functions of adenosine are promoted by the activation of A2A. But, during hypoxia and mechanical ventilation the excess production of adenosine also activates A2B [67]. In particular, a dose-dependent response of pulmonary permeability [68], reduction of interleukins, TNF- $\alpha$ and chemokines with attenuation of the inflammatory cellular response [69] has been observed. A2B has a lower affinity for adenosine. Anyway, in pathological conditions of hypoxia and extensive inflammation it is activated to counteract the inflammatory response and prevent further damage. To date, the standard treatment for ARDS remains respiratory support therapy such as ventilation with oxygen at high concentrations. However, iatrogenic hyperoxygenation is likely to weaken the anti-inflammatory action of adenosine. In fact, the signaling of adenosine and in particular of the A2A receptor is activated in conditions of hypoxia, as in the ischemia reperfusion model. Under severe conditions and dysregulated inflammation, such as in COVD-19, hyperoxygenation may exacerbate lung damage. This phenomenon has been studied in the animal model. It has been highlighted that during hyperoxygenation the enhancement of the adenosine signaling protects the lung tissue and contrarily a weakening causes greater damage [6].

\section{Obesity and susceptibility to the cytokine storm}

A paradox of obesity was its protective role in pneumonia [70]. Conversely, in COVID-19 obesity leads to an increased risk of death. This occurs on at least three distinct levels: respiratory dysfunction; comorbidity; increased metabolic risk [71].

The obese patient is characterized by lower respiratory compliance and a reduction in function and reserve volumes. The expansion of abdominal fat compromises diaphragmatic excursion and ventilation [72]. In fact, among hospitalized patients, the obese have higher access to intensive care units and more serious ventilatory dysfunctions. Moreover, together with breathing difficulties, higher levels of inflammation and impaired immune response are associated [73]. Age, obesityrelated diseases and obesity itself have been identified as risk factors for the development of severe forms and death due to COVID-19 [74, 75]. Finally, obesity has been shown to be an independent risk factor in young males [76]. The main comorbidities include hypertension, impaired renal function, 
diabetes mellitus and cardiometabolic diseases [71]. Metabolic syndrome has been recognized as high risk factor in patients with COVID-19. In fact, it is frequent in obese patients and, due to its complex and multifactorial nature, it is a trigger for the cytokine storm typical of SarS-CoV2 infection [77, 78]. The role of hypertension has been recognized in worsening the clinical outcome in patients with COVID-19. Also, anti-hypertensive therapy has been much discussed and it is believed to make the patient more susceptible to infection and disease [79-81]. Alteration of renal function, together with hypovitaminosis D, results in a negative modulation of the anti-inflammatory response [79]. Diabetes mellitus has proven to be a risk factor in current SarS-CoV-2 infection, SarS and Mers [82]. Hyperglycemia interacts in the recognition by the immune system of the pathogen and it is one of the causes of the reduced immune response [79]. In addition, it has been hypothesized that uncontrolled hyperglycemia favors infection, due to a change in ACE2 glycosylation [83].

Furthermore, a role of epicardial fat (EAT) in high mortality from COVID-19 has been highlighted. During disease, EAT produces abundantly pro-inflammatory adipokines which act negatively on the heart and contribute to the cytokine cascade and immune dysfunction [84].

Obesity and its comorbidities increase the patient's inflammatory status, resulting in a higher inflammation set-point and makes it more susceptible to infection. This phenomenon has been called immuno-innate memory and is attributable to epigenetic changes that we know to be influenced by the environment, lifestyle and poor nutrition [3].

In summary, obesity disease predisposes to a greater risk of getting sick, being more contagious and even having a greater delay in viral clearance [85]. In light of the costs of cardiometabolic complications related to obesity, and today COVID-19, the need for screening and preventive programs aimed at treating obesity is indisputable (Figure 1). 
Figure 1. Mechanisms of Adenosine Action on COVID-19

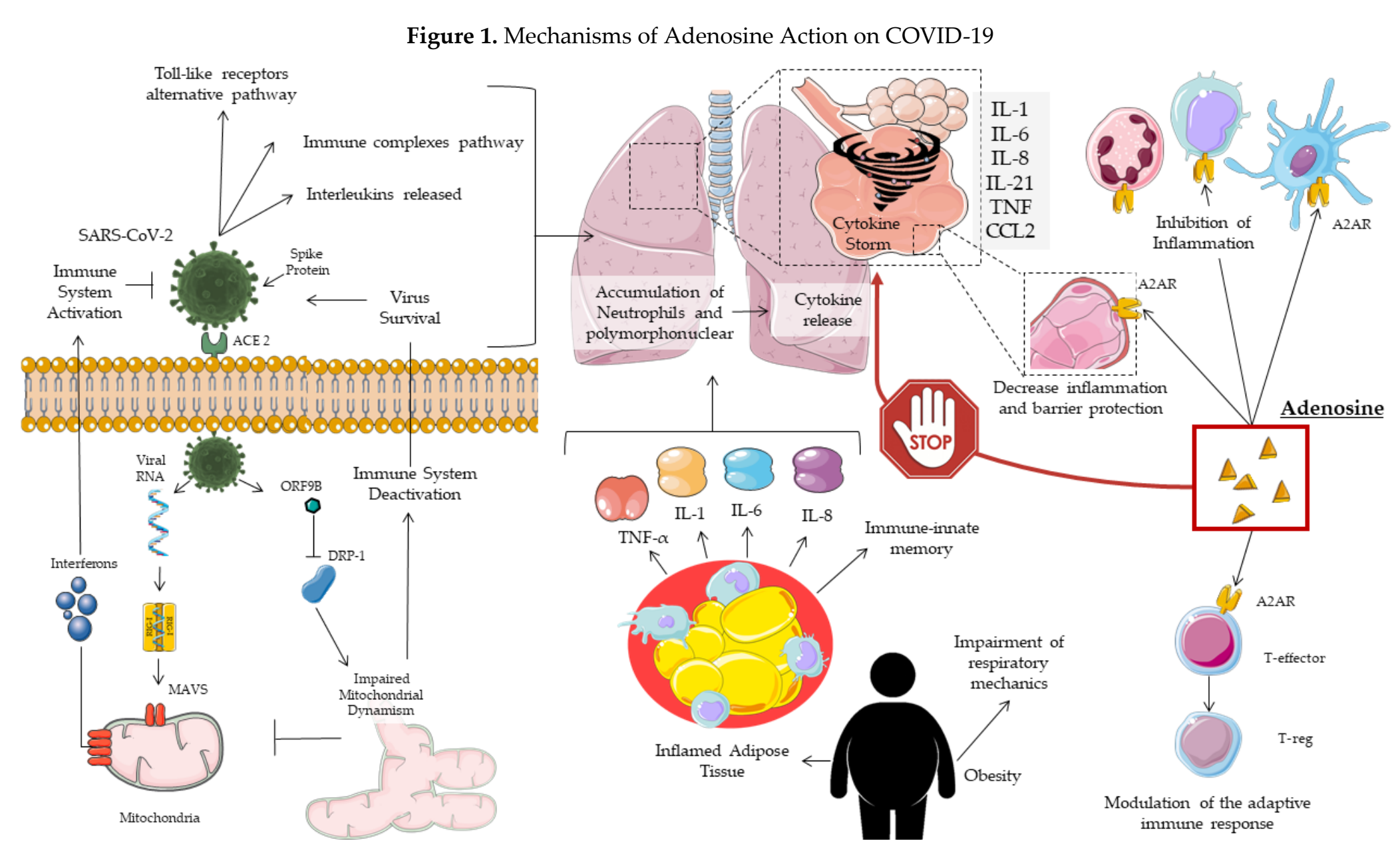




\section{Tocilizumab in COVID-19 patient}

TCZ is a monoclonal antibody against interleukin-6 (IL-6). Recently, TCZ was used in COVID-19 patients as an alternative treatment because of the cytokine storm in severe forms of the disease, and important cause of death. Classically, TCZ is known as a rheumatic drug. Interestingly, COVID-19 patients have features mimicking rheumatic diseases, such as arthralgias, acute interstitial pneumonia, myocarditis, leucopenia, lymphopenia, thrombocytopenia and cytokine storm. In particular, IL-6 plays a crucial role in this release syndrome. Therefore, the use of TCZ found its rational [86-90].

Literature data are growing on this issue. There are few clinical studies and frequently the population sample is not homogenous.

A clinical study on 100 COVID-19 patients affected by pneumonia with acute respiratory distress syndrome (ARDS) and characterized by hyperinflammatory syndrome, demonstrated a rapid and sustained response associated with significant clinical improvement to TCZ treatment [91]. Another Italian study on 63 patients with severe COVID-19 showed an improvement in respiratory and laboratory parameters [92]. While, TCZ administration did not reduce ICU admission or mortality rate in a cohort of 21 patients [93]. In addition, TCZ has a positive impact if used early during pneumonia with severe respiratory syndrome in terms of increased survival and favorable clinical course in 83 patient studied [94]. Interestingly, TCZ reduced the number of ICU admissions and/or mortality in 20 patients with severe SARS-CoV-2 pneumonia [95].

Lou et al suggested the use of TCZ in COVID-19 patients at risk of cytokine storm, with the limit of 15 patients with different clinical features [96]. In addition, TCZ showed an improvement in clinical outcome and a reduction of mortality in 19 severe and critical COVID-19 patients [97]. TCZ was adopted with good results in a case of Multiple Myeloma [98], in another of metastatic sarcomatoid clear renal cell carcinoma [5], in a systemic sclerosis patient [99], in a kidney transplant recipient patient -single dose- [100] and in a young patient [101]. On the other hand, same clinical case highlights adverse effects of TCZ suggesting selection of optimal patient and timing during this disease process [102], such as acute hypertriglyceridemia [103]. A known side effect of TCZ used in rheumatology is osteonecrosis of the jaws [104] and intestinal perforation [105]. Recently, a press release from the Italian Drug Agency (AIFA) reported that the early administration of TCZ in COVID19 patients did not lead to relevant clinical benefits. The potential of TCZ in selected patient subgroups remains to be clarified [4].

\section{Clinical Case}

Hereafter, we describe the clinical case of a patient with COVID-19 hospitalized at the Great Metropolitan Bianchi Melacrino Morelli (GOM) Hospital in Reggio Calabria, Italy. The patient for lack of clinical improvement was given charitable therapy with Adenosine via the inhalation route. The patient was monitored daily and subjected to instrumental tests. Computed tomography (CT) scan was performed at baseline and after treatment and results were analyzed by the same radiologist. The detections of SARS-Cov-2 in upper or lower upper or lower respiratory tract was performed at admission and at baseline, 48 hours, 120 hours and 15 days after the beginning of treatment. The detection of SARS-Cov-2 was evaluated by laboratory of Microbiology\& Virology of the GOM. Upper (nasopharyngeal swabs) and lower (broncho-alveolar lavages, broncho-aspirates and tracheal aspirates) respiratory tract specimens, were collected using Copan Universal Transport Medium 
(UTM-RT®) System or sterile container at $4^{\circ} \mathrm{C}$ and processed within 24 hours. RNA-COVID-19 was evaluated by using an Allplex 2019-nCoV Assay that identifies three different target genes: E (envelope), RdRp (RNA-dependent RNA polymerase, and N (nucleoprotein gene) according to the international recommended guidelines by the World Health Organization. This test has also received CE-IVD mark and KFDA approval. The test assay was performed following the manufacturer's instructions. According to the interpretation criteria, detection of only one of multiple genes has been interpreted as COVID-19 positive. Inhalatory adenosine was nebulized and dispensed by an Aerogen USB Controller linked to a high flux device with $21 \% \mathrm{FiO} 2$, a flow of $60 \mathrm{l} / \mathrm{m}$ in five minutes. Adenosine at the dosage of 9 mg every 12 hours in the first 24 hours and subsequently, every 24 days for four consecutive days. Inhaled adenosine dose was extrapolated from the preclinical studies in mice [106-109] as well as from the clinical studies using adenosine as aerosol formulation, showing dose limiting efficacy over $10 \mathrm{mg}$ and no adverse events in normal individuals and patients with nonasthmatic disease [107-111]. The off-label treatment and patient monitoring was approved by the Hospital Safety Team and by the Ethical Committee of South Calabria. Patients' privacy and sensitive data were appropriately protected.

On March 31, 2020, a 58-year-old man normal weight for BMI (24.8 kg m2) was hospitalized for acute respiratory failure with hypoxemia COVID-19-related. Of note in remote pathological history, OSAS and previous surgery for removal of an epidermoid cyst of the left ponto-cerebellar corner were reported.

The chest CT examination of March 31 was performed in basal conditions but significantly limited by the patient's lack of ability to maintain adequate respiratory kinetics. Thickening-consolidating areas of the lungs and mantles with a tendency to confluence to the lower lobes were observed. Furthermore, ground-glass opacity and increased density, the presence of consolidating components extensively interesting the upper lobes, with associated widespread reticular interstitial thickening were reported. Also, Ground Glass areas with blurred contours in correspondence of the anteromedial segment of the right upper lobe (RUL), presence of crazy paving lesions in the lower lobes, presence of pseudonodular-looking fibrosclerotic lesions arranged in clusters bilaterally in the lower lobes were found. Again, pleuroparenchymal fibrosis of probable disventilatory nature was present in the posterior basal segments of both lower lobes. Mediastinal lymphadenomegalies were not evident. From April 1, 2020, the patient was treated with low molecular weight heparin 4000 IU twice daily until discharge. While hydroxychlororoquine 200mg twice daily, Azithromycin once daily and oxygen therapy with Ventimask were administered until April 13. After two weeks following admission, due to the absence of improvement in respiratory failure with an average $\mathrm{PaO} 2 / \mathrm{FiO} 2$ value $<250$, the patient was offered charitable treatment. The patient was informed and received offlabel treatment with inhalatory adenosine.

After 5 days since the first administration of inhalatory adenosine, a rapid increase in PaO2/FiO2 has been observed, up to an average value $>400$, with improvement of biochemical parameters (Table 1), respiratory failure and interruption of respiratory support.

Furthermore, with regard to the detection of Sars-CoV-2 on nasopharyngeal swabs, a positivity was observed only for the $\mathrm{N}$ gene on April 17. In the following detections, carried out as per protocol every 2 days, it was always found negative.

Finally, the CT-scan of April 20 was performed under basal conditions and with High Resolution-CT acquisition. A reduction in the ground glass opacities, only appreciated in the antero-medial segment 
of the RUL, a reduction in the crazy paving aspect, and a reduction of lung mantle thickening lesions were observed. Pleuroparenchial fibrosis was no longer detectable and there was only one residue to the right of a thin pleuroparenchymal stria with millimetric fibrotic pseudonodules. The picture appeared to be significantly improved compared to the previous CT-scans (Figure 2).

During and after treatment, adverse events related to the use of adenosine have not been observed.

Table 1. Biochemical Parameters

\begin{tabular}{cccc}
\hline Parameters & \multicolumn{3}{c}{ Time } \\
\hline RBC $(\times 106 / \mu \mathrm{L})$ & 5,12 & 4,8 & 4,54 \\
HGB $(\mathrm{g} / \mathrm{dL})$ & 16,2 & 14,8 & 13,8 \\
PLT $(\times 103 / \mu \mathrm{L})$ & 132 & 301 & 185 \\
WBC $(x 103 / \mu \mathrm{L})$ & 2,74 & 4,32 & 3,33 \\
NEU $(\times 103 / \mu \mathrm{L})$ & 2,14 & 2,93 & 1,85 \\
LYMPH $(x 103 / \mu \mathrm{L})$ & 0,39 & 0,9 & 0,95 \\
CRP $(\mu \mathrm{g} / \mathrm{dL})$ & 52,4 & 3,14 & 3,14 \\
D-DIMER $(\mu \mathrm{g} / \mathrm{L})$ & 220 & 290 & 50 \\
\hline
\end{tabular}

RBC: Red Blood Cells; HGB: Haemoglobin; PLT: Platelets; WBC: White Blood Cells; LYMPH: Lymphocytes; CRP: C-Reactive Protein. 
Figure 2. Comparison between admission (A) and follow-up (B) CT-Scans, in different section.

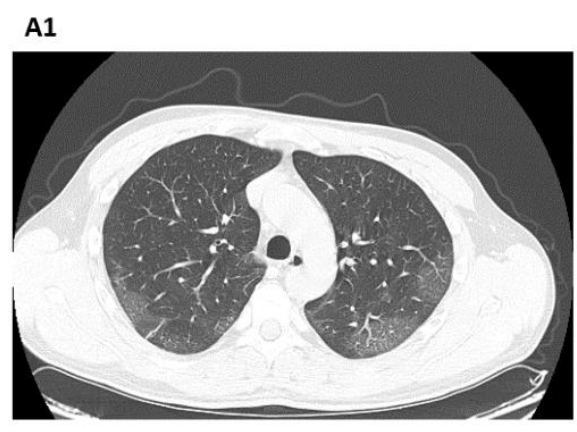

A2

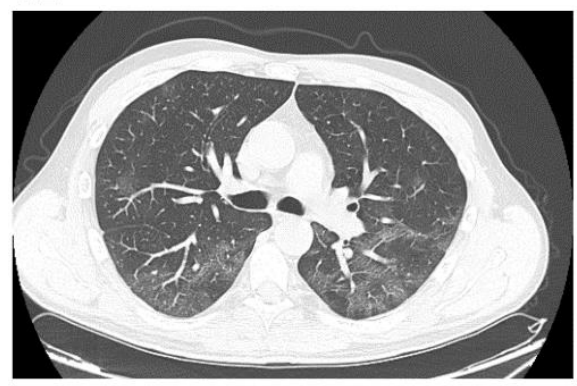

A3

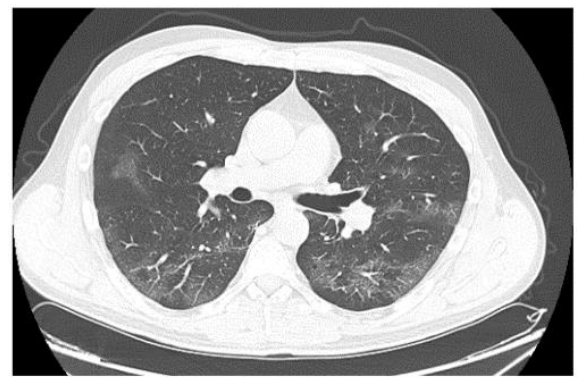

A4

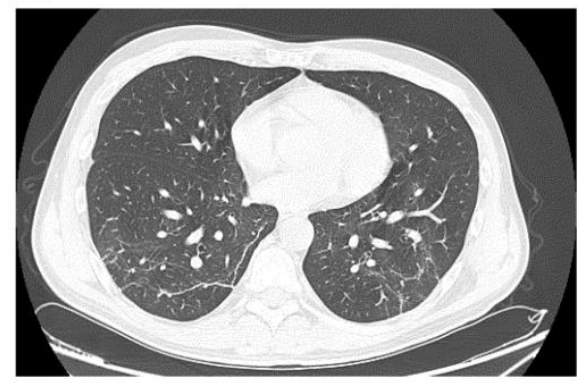

A5

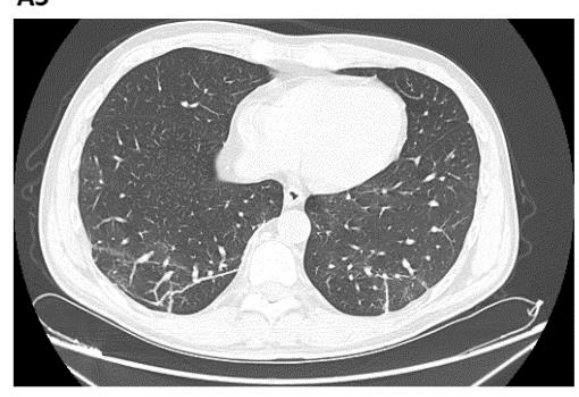

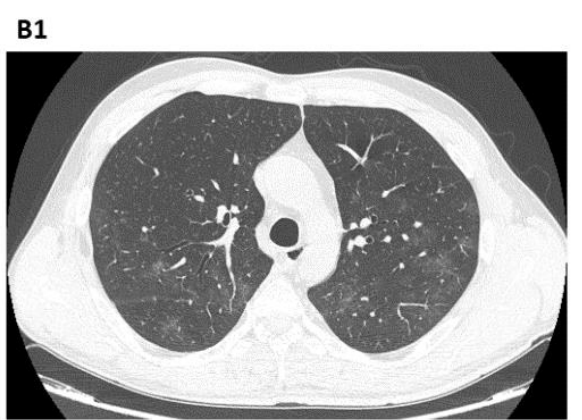

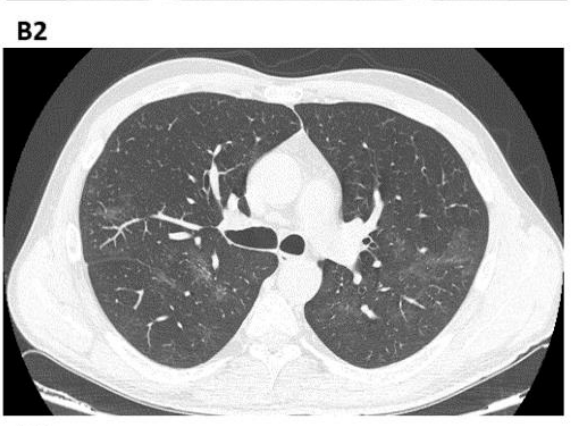

B3

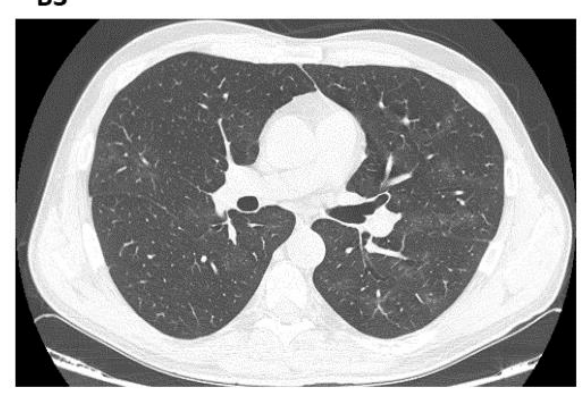

B4

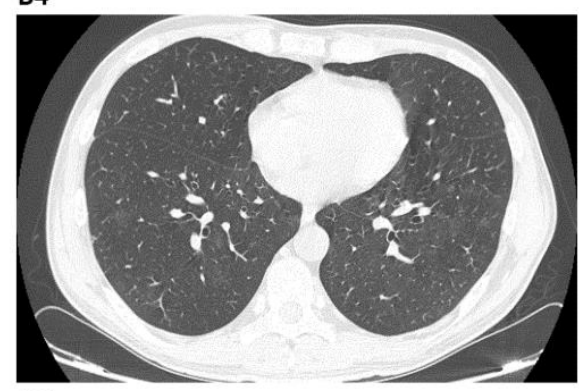

B5

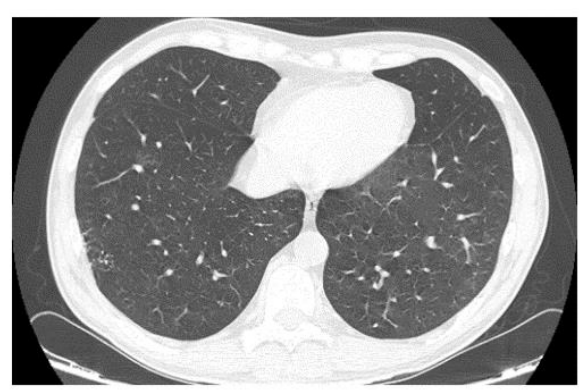




\section{Conclusions}

Currently inhaled adenosine is used for provocation tests, with a maximum tolerable dose of up to $40 \mathrm{mg}$. Furthermore, its therapeutic use in ARDS had already been hypothesized.

For this reason, a COVID-19 patient, who showed no clinical improvement with the therapies already applied, was treated with inhaled adenosine, with a $21 \%$ oxygen mixture, due to its pathways. In 5 days, it was possible to observe a negative effect on the detection of SarS-CoV2 and the resolution of respiratory failure and the radiological picture.

Factors concurrent to the COVID-19 cytokine storm are several. These include obesity and its comorbidities [112-115], a pathological condition that can no longer be overlooked, given the cost of human lives paid.

Given this, the use of adenosine can be a valid therapeutic option in COVID-19 ARDS.

To overcome the only compassionate use of adenosine, it is hoped that randomized controlled trials for ARDS resolution, with a cytokine storm, will be launched.

Author Contributions: For research articles with several authors, a short paragraph specifying their individual contributions must be provided. The following statements should be used "Conceptualization, C.F., M.C., P.C., S.M., A.D.L.; resources, E.G.V., S.L.C., M.T., A.F.; data curation, L.R.; writing-original draft preparation, L.R., A.D.L..; writing - review and editing, C.F., M.C., P.C., S.M., E.G.V., S.L.C., M.T., R.D., L.R., A.D.L.; visualization, L.R.; supervision, A.D.L. All authors have read and agreed to the published version of the manuscript.

Funding: This research received no external funding.

Acknowledgments: The authors are grateful to all GOM health workers.

Conflicts of Interest: The authors declare no conflict of interest.

$\begin{array}{ll}\text { Abbreviations } \\ \text { ARDS } & \text { Acute Respiratory Distress Syndrome } \\ \text { IL } & \text { Interleukin } \\ \text { TCZ } & \text { Tocilizumab } \\ \text { JAK } & \text { Janus kinase inhibitors } \\ \text { A2AR } & \text { A2A receptor } \\ \text { MOF } & \text { Multi organ failure } \\ \text { TNF- } \alpha & \text { Tumor Necrosis Factor- } \alpha \\ \text { hCoV } & \text { Human Coronavirus } \\ \text { DRP } & \text { Dynamin-related proteins } \\ \text { PINK-1 } & \text { PTEN-induced kinase 1 } \\ \text { RIG-I } & \text { Retinoic acid-inducible gene 1 } \\ \text { RLRs } & \text { RIG-I-like Receptors } \\ \text { MAVS } & \text { Mitochondrial associated antiviral signaling protein } \\ \text { CARDs } & \text { Caspase recruitment domains } \\ \text { NFkB } & \text { Nuclear factor kappa-light-chain-enhancer of activated B cells } \\ \text { ORF } & \text { Open Reading Frame } \\ \text { INF } & \text { Interferon } \\ \text { TRAF } & \text { TNF Receptor Associated Factor } \\ \text { PMN } & \text { Polymorphonuclear leukocytes } \\ \text { ADP } & \text { Adenosine diphosphate } \\ \text { ATP } & \text { Adenosine triphosphate } \\ \text { AMP } & \text { Adenosine monophosphate } \\ \text { CD } & \text { Cluster of Differentiation } \\ \text { ALI } & \text { Acute lung injury } \\ \text { AR } & \text { Adenosine receptors } \\ \text { CXCL1-3 } & \text { Chemokine (C-X-C motif) ligand 3 } \\ \text { T Regs } & \text { Regulatory T cells } \\ \text { PPAR } \gamma & \text { Peroxisome proliferator-activated receptor } \gamma \\ & \end{array}$


ACE2

EAT

GOM

CT

RUB
Angiotensin-converting enzyme

epicardial fat

Great Metropolitan Bianchi Melacrino Morelli

Computed tomography

Right upper lobe

\section{References}

1. WHO Coronavirus Disease (COVID-19) Dashboard. Available online: https://covid19.who.int/?gclid=Cj0KCQjw0rr4BRCtARIsAB0_48NF8a417ap3xz5a6rC5bv 4LHq4iaWP5iTQPyvEhFlQLpGa7fyo6R0aAhVTEALw_wcB (accessed on 15 July 2020).

2. Ye, Q.; Wang, B.; Mao, J. The pathogenesis and treatment of the 'Cytokine Storm' in COVID-19. J Infect 2020, 80, 607-613. doi: 10.1016/j.jinf.2020.03.037.

3. Roschewski, M.; Lionakis, M.S.; Sharman, J.P.; Roswarski, J.; Goy, A.; Monticelli, M.A.; Roshon, M.; Wrzesinski, S.H.; Desai, J.V.; Zarakas, M.A.; Collen, J.; Rose, K.; Hamdy, A.; Izumi, R.; Wright, G.W.; Chung, K.K.; Baselga, J.; Staudt, LM.; Wilson, W.H. Inhibition of Bruton tyrosine kinase in patients with severe COVID-19. Sci Immunol 2020, 5, eabd0110. doi: 10.1126/sciimmunol.abd0110.

4. AIFA. COVID-19: Studio randomizzato italiano, nessun beneficio dal tocilizumab. Available online: https://www.aifa.gov.it/-/covid-19-studio-randomizzato-italianonessun-beneficio-dal-tocilizumab (accessed on 23 June 2020)

5. Michot, J.M.; Albiges, L.; Chaput, N.; Saada, V.; Pommeret, F.; Griscelli, F.; Balleyguier, C.; Besse, B.; Marabelle, A.; Netzer, F.; Merad, M.; Robert, C.; Barlesi, F.; Gachot, B.; Stoclin, A. Tocilizumab, an anti-IL-6 receptor antibody, to treat COVID-19-related respiratory failure: a case report. Ann Oncol 2020, 31, 961-964. doi: 10.1016/j.annonc.2020.03.300.

6. Thiel, M.; Chouker, A.; Ohta, A.; Jackson, E.; Caldwell, C.; Smith, P.; Lukashev, D.; Bittmann, I.; Sitkovsky, M.V. Oxygenation inhibits the physiological tissue-protecting mechanism and thereby exacerbates acute inflammatory lung injury. Version 2. PLoS Biol 2005, 3, e174. doi: 10.1371/journal.pbio.0030174.

7. Law, H.K.W.; Cheung, C.Y.; Ng H.Y.; Sia, S.F.; Chan, Y.O.; Luk, W. Chemokine upregulation in SARS-coronavirus-infected, monocyte-derived human dendritic cells. Blood 2005, 106, 2366-2374. doi: 10.1182/blood-2004-10-4166.

8. Cheung, C.Y.; Poon, L.L.M.; Ng. I.H.Y.; Luk, W.; Sia, S.-F.; Wu, M.H.S. Cytokine responses in severe acute respiratory syndrome coronavirus-infected macrophages in vitro: possible relevance to pathogenesis. J Virol 2005, 79, 7819-7826. doi:10.1128/JVI.79.12.7819-7826.2005.

9. Lau, S.K.P.; Lau, C.C.Y.; Chan, K.-H.; Li, C.P.Y.; Chen, H.; Jin, D.-Y. Delayed induction of proinflammatory cytokines and suppression of innate antiviral response by the novel Middle East respiratory syndrome coronavirus: implications for pathogenesis and treatment. J Gen Virol 2013, 94, 2679-2690. doi: 10.1099/vir.0.055533-0.

10. Kim, E.S.; Choe, P.G.; Park, W.B.; Oh, H.S.; Kim, E.J.; Nam, E.Y.; Na, S.H.; Kim, M.; Song, K.H.; Bang, J.H.; Park, S.W.; Kim, H.B.; Kim, N.J.; Oh, M.D. Clinical Progression and Cytokine Profiles of Middle East Respiratory Syndrome Coronavirus Infection. J Korean Med Sci 2016, 31, 1717-1725. https://doi.org/10.3346/jkms.2016.31.11.1717.

11. Ng. D.L.; Al Hosani, F.; Keating, M.K.; Gerber, S.I.; Jones, T.L.; Metcalfe, M.G. Clinicopathologic, immunohistochemical, and ultrastructural findings of a fatal case of 
middle east respiratory syndrome coronavirus infection in the United Arab Emirates, April 2014. Am J Pathol 2016, 186, 652-658. doi: 10.1016/j.ajpath.2015.10.024.

12. Chien, J.Y.; Hsueh, P.R:; Cheng, W.C.; Yu, C.J.; Yang, P.C. Temporal changes in cytokine/chemokine profiles and pulmonary involvement in severe acute respiratory syndrome. Respirology 2006, 11, 715-22. doi: 10.1111/j.1440-1843.2006.00942.x.

13. Zhang, Y.; Li, J.; Zhan, Y.; Wu, L.; Yu, X.; Zhang, W.; Ye, L.; Xu, S.; Sun, R.; Wang, Y.; Lou, $\mathrm{J}$. Analysis of serum cytokines in patients with severe acute respiratory syndrome. Infect Immun 2004, 72, 4410-5. doi: 10.1128/IAI.72.8.4410-4415.2004.

14. Channappanavar, R.; Fehr, A.R.; Zheng, J.; Wohlford-Lenane, C.; Abrahante, J.E.; Mack, M.; Sompallae, R.; McCray, P.B.Jr.; Meyerholz, D.K. .; Perlman, S. IFN-I response timing relative to virus replication determines MERS coronavirus infection outcomes. J Clin Invest, 2019, 130, 3625-3639. doi: 10.1172/JCI126363.

15. Smits, S.L.; de Lang, A.; van den Brand, J.M.; Leijten, L.M.; van IJcken, W.F.; Eijkemans, M.J.; van Amerongen, G.; Kuiken, T.; Andeweg, A.C.; Osterhaus, A.D.; Haagmans, B.L. Exacerbated innate host response to SARS-CoV in aged non-human primates. PLoS Pathog 2010, 6, e1000756. doi: 10.1371/journal.ppat.1000756.

16. Cameron, M.J.; Bermejo-Martin, J.F.; Danesh, A.; Muller, M.P.; Kelvin, D.J. Human immunopathogenesis of severe acute respiratory syndrome (SARS). Virus Res 2008, 133, 13-9. doi: 10.1016/j.virusres.2007.02.014.

17. Huang, C.; Wang, Y.; Li, X.; Ren, L.; Zhao, J.; Hu, Y.; Zhang, L.; Fan, G.; Xu, J.; Gu, X.; Cheng, Z.; Yu, T.; Xia, J.; Wei, Y.; Wu, W.; Xie, X.; Yin, W.; Li, H.; Liu, M.; Xiao, Y.; Gao, H.; Guo, L.; Xie, J.; Wang, G.; Jiang, R.; Gao, Z.; Jin, Q.; Wang, J.; Cao, B. Clinical features of patients infected with 2019 novel coronavirus in Wuhan, China. Lancet 2020, 395, 497506. doi: 10.1016/S0140-6736(20)30183-5.

18. McBride, H.M.; Neuspiel, M.; Wasiak, S. Mitochondria: more than just a powerhouse. Curr Biol. 2006, 16, R551-60. doi: 10.1016/j.cub.2006.06.054.

19. Anand, S.K.; Tikoo, S.K. Viruses as modulators of mitochondrial functions. Adv Virol 2013, 2013, 738794. doi: 10.1155/2013/738794.

20. Khan, M.; Syed, G.H.; Kim, S.J.; Siddiqui, A. Mitochondrial dynamics and viral infections: A close nexus. Version 2. Biochim Biophys Acta 2015, 1853, 2822-33. doi: 10.1016/j.bbamcr.2014.12.040.

21. Losón, O.C.; Song, Z.; Chen, H.; Chan, D.C. Fis1, Mff, MiD49, and MiD51 mediate Drp1 recruitment in mitochondrial fission. Mol Biol Cell 2013, 24, 659-67. doi: 10.1091/mbc.E1210-0721.

22. Narendra, D.P.; Jin, S.M.; Tanaka, A.; Suen, D.F.; Gautier, C.A.; Shen, J.; Cookson, M.R.; Youle, R.J. PINK1 is selectively stabilized on impaired mitochondria to activate Parkin. PLoS Biol 2010, 8, e1000298. doi: 10.1371/journal.pbio.1000298.

23. Chen, H.; Chan, D.C. Mitochondrial dynamics--fusion, fission, movement, and mitophagy--in neurodegenerative diseases. Hum Mol Genet 2009, 18, R169-76. doi: 10.1093/hmg/ddp326.

24. Seth, R.B.; Sun, L.; Ea, C.K.; Chen, Z.J. Identification and characterization of MAVS, a mitochondrial antiviral signaling protein that activates NF-kappaB and IRF 3. Cell 2005, 122, 669-82. doi: 10.1016/j.cell.2005.08.012. 
25. Shi, C.S.; Qi, H.Y.; Boularan, C.; Huang, N.N.; Abu-Asab, M.; Shelhamer, J.H.; Kehrl, J.H. SARS-coronavirus open reading frame-9b suppresses innate immunity by targeting mitochondria and the MAVS/TRAF3/TRAF6 signalosome. J Immunol 2014, 193, 3080-9. doi: 10.4049/jimmunol.1303196.

26. Yoshimoto, F.K. The Proteins of Severe Acute Respiratory Syndrome Coronavirus-2 (SARS CoV-2 or n-COV19), the Cause of COVID-19. Protein J 2020, 39, 198-216. doi: 10.1007/s10930-020-09901-4.

27. Wang, C.; Liu, Z.; Chen, Z.; Huang, X.; Xu, M.; He, T.; Zhang, Z. The establishment of reference sequence for SARS-CoV-2 and variation analysis. J Med Virol 2020, 13, 10.1002/jmv.25762. doi: 10.1002/jmv.25762.

28. Le, T.T.; Berg, N.K.; Harting, M.T.; Li, X.; Eltzschig, H.K.; Yuan, X. Purinergic Signaling in Pulmonary Inflammation. Front Immunol 2019, 10: 1633. doi: 10.3389/fimmu.2019.01633.

29. Eltzschig, H.K.; Eckle, T. Ischemia and reperfusion--from mechanism to translation. Nat Med 2011, 17, 1391-401. doi: 10.1038/nm.2507.

30. Hart, M.L.; Gorzolla, I.C.; Schittenhelm, J.; Robson, S.C.; Eltzschig, H.K. SP1-dependent induction of CD39 facilitates hepatic ischemic preconditioning. J Immunol 2010, 184, 401724. doi: 10.4049/jimmunol.0901851.

31. Morote-Garcia, J.C.; Rosenberger, P.; Nivillac, N.M.; Coe, I.R.; Eltzschig, HK. Hypoxiainducible factor-dependent repression of equilibrative nucleoside transporter 2 attenuates mucosal inflammation during intestinal hypoxia. Gastroenterology 2009, 136, 607-18. doi: 10.1053/j.gastro.2008.10.037.

32. Eltzschig, H.K.; Faigle, M.; Knapp, S.; Karhausen, J.; Ibla, J.; Rosenberger, P.; Odegard, K.C.; Laussen, P.C.; Thompson, L.F.; Colgan, S.P. Endothelial catabolism of extracellular adenosine during hypoxia: the role of surface adenosine deaminase and CD26. Blood 2006, 108, 1602-10. doi: 10.1182/blood-2006-02-001016.

33. Morote-Garcia, J.C.; Rosenberger, P.; Kuhlicke, J.; Eltzschig, H.K. HIF-1-dependent repression of adenosine kinase attenuates hypoxia-induced vascular leak. Blood 2008, 111, 5571-80. doi: 10.1182/blood-2007-11-126763.

34. Cronstein, B.N. Adenosine, an endogenous anti-inflammatory agent. J Appl Physiol (1985) 1994, 76, 5-13. doi: 10.1152/jappl.1994.76.1.5.

35. Linden, J. Molecular approach to adenosine receptors: receptor-mediated mechanisms of tissue protection. Annu Rev Pharmacol Toxicol 2001, 41, 775-87. doi: 10.1146/annurev.pharmtox.41.1.775.

36. Haselton, F.R.; Alexander, J.S.; Mueller, S.N. Adenosine decreases permeability of in vitro endothelial monolayers. J Appl Physiol (1985), 1993, 74, 1581-90. doi: 10.1152/jappl.1993.74.4.1581.

37. Haskó, G.; Cronstein, B.N. Adenosine: an endogenous regulator of innate immunity. Trends Immunol 2004, 25, 33-9. doi: 10.1016/j.it.2003.11.003.

38. Salvatore, C.A.; Jacobson, M.A.; Taylor, H.E.; Linden, J.; Johnson, R.G. Molecular cloning and characterization of the human A3 adenosine receptor. Proc Natl Acad Sci U S A, 1993, 90, 10365-9. doi: 10.1073/pnas.90.21.10365. 
39. Chunn, J.L.; Young, H.W.; Banerjee, S.K.; Colasurdo, G.N.; Blackburn, M.R. Adenosinedependent airway inflammation and hyperresponsiveness in partially adenosine deaminase-deficient mice. J Immunol 2001, 167, 4676-85. doi: 10.4049/jimmunol.167.8.4676.

40. Blackburn, M.R.; Lee, C.G.; Young, H.W.; Zhu, Z.; Chunn, J.L.; Kang, M.J.; Banerjee, S.K.; Elias, J.A. Adenosine mediates IL-13-induced inflammation and remodeling in the lung and interacts in an IL-13-adenosine amplification pathway. J Clin Invest 2003, 112, 332-44. doi: 10.1172/JCI16815.

41. Jolin, A.; Myklebust, R.; Olsen, R.; Bjertnaes, L.J. Adenosine protects ultrastructure of isolated rat lungs against fat emulsion injury. Acta Anaesthesiol Scand 1994, 38, 75-81. doi: 10.1111/j.1399-6576.1994.tb03841.x.

42. Ware, L.B.; Matthay, M.A. The acute respiratory distress syndrome. N Engl J Med 2000, 342, 1334-49. doi: 10.1056/NEJM200005043421806.

43. Adkins, W.K.; Barnard, J.W.; Moore, T.M.; Allison, R.C.; Prasad, V.R.; Taylor, A.E. Adenosine prevents PMA-induced lung injury via an A2 receptor mechanism. J Appl Physiol (1985) 1993, 74, 982-8. doi: 10.1152/jappl.1993.74.3.982.

44. Koeppen, M.; Eckle, T.; Eltzschig, H.K. Selective deletion of the A1 adenosine receptor abolishes heart-rate slowing effects of intravascular adenosine in vivo. PLoS One 2009, 4, e6784. doi: 10.1371/journal.pone.0006784.

45. Wilson, CN.; Batra, V.K. Lipopolysaccharide binds to and activates $\mathrm{A}(1)$ adenosine receptors on human pulmonary artery endothelial cells. J Endotoxin Res 2002, 8, 263-71. doi: 10.1179/096805102125000470.

46. Yaar, R.; Jones, M.R.; Chen, J.F.; Ravid, K. Animal models for the study of adenosine receptor function. J Cell Physiol 2005, 202, 9-20. doi: 10.1002/jcp.20138.

47. Murphree, L.J.; Sullivan, G.W.; Marshall, M.A.; Linden, J. Lipopolysaccharide rapidly modifies adenosine receptor transcripts in murine and human macrophages: role of NFkappaB in $\mathrm{A}(2 \mathrm{~A})$ adenosine receptor induction. Biochem J 2005, 391, 575-80. doi: 10.1042/BJ20050888.

48. Ohta, A.; Sitkovsky, M. Role of G-protein-coupled adenosine receptors in downregulation of inflammation and protection from tissue damage. Nature, 2001, 414, 916-20. doi: 10.1038/414916a.

49. Haskó, G.; Pacher, P. A2A receptors in inflammation and injury: lessons learned from transgenic animals. J Leukoc Biol 2008, 83, 447-55. doi: 10.1189/jlb.0607359.

50. Bonneau, O.; Wyss, D.; Ferretti, S.; Blaydon, C.; Stevenson, C.S.; Trifilieff, A. Effect of adenosine A2A receptor activation in murine models of respiratory disorders. Am J Physiol Lung Cell Mol Physiol 2006, 290, L1036-43. doi: 10.1152/ajplung.00422.2005.

51. Reutershan, J.; Cagnina, R.E.; Chang, D.; Linden, J.; Ley, K. Therapeutic anti-inflammatory effects of myeloid cell adenosine receptor A2a stimulation in lipopolysaccharide-induced lung injury. J Immunol 2007, 179,1254-63. doi: 10.4049/jimmunol.179.2.1254.

52. Fredholm, B.B. Adenosine, an endogenous distress signal, modulates tissue damage and repair. Cell Death Differ 2007, 14, 1315-23. doi: 10.1038/sj.cdd.4402132.

53. Yang, D.; Zhang, Y.; Nguyen, H.G.; Koupenova, M.; Chauhan, A.K.; Makitalo, M.; Jones, M.R.; St Hilaire, C.; Seldin, D.C.; Toselli, P.; Lamperti, E.; Schreiber, B.M.; Gavras, H.; 
Wagner, D.D.; Ravid, K. The A2B adenosine receptor protects against inflammation and excessive vascular adhesion. J Clin Invest 2006, 116, 1913-23. doi: 10.1172/JCI27933.

54. Bouma, M.G.; Jeunhomme, T.M.; Boyle, D.L.; Dentener, M.A.; Voitenok, N.N.; van den Wildenberg, F.A.; Buurman, W.A. Adenosine inhibits neutrophil degranulation in activated human whole blood: involvement of adenosine $\mathrm{A} 2$ and $\mathrm{A} 3$ receptors. J Immunol 1997, 158, 5400-8.

55. Avni, I.; Garzozi, H.J.; Barequet, I.S.; Segev, F.; Varssano, D.; Sartani, G.; Chetrit, N.; Bakshi, E.; Zadok, D.; Tomkins, O.; Litvin, G.; Jacobson, K.A.; Fishman, S.; Harpaz, Z.; Farbstein, M.; Yehuda, S.B.; Silverman, M.H.; Kerns, W.D.; Bristol, D.R.; Cohn, I.; Fishman P. Treatment of dry eye syndrome with orally administered CF101: data from a phase 2 clinical trial. Ophthalmology 2010, 117, 1287-93. doi: 10.1016/j.ophtha.2009.11.029.

56. Layland, J.; Carrick, D.; Lee, M.; Oldroyd, K.; Berry, C. Adenosine: physiology, pharmacology, and clinical applications. JACC Cardiovasc Interv 2014, 7, 581-91. doi: 10.1016/j.jcin.2014.02.009.

57. Schepp, C.P.; Reutershan, J. Bench-to-bedside review: adenosine receptors--promising targets in acute lung injury? Crit Care 2008, 12, 226. doi: 10.1186/cc6990.

58. Antoniol1i, L.; Blandizzi, C.; Pacher, P.; Haskó, G. The Purinergic System as a Pharmacological Target for the Treatment of Immune-Mediated Inflammatory Diseases. Pharmacol Rev 2019, 71, 345-382. doi: 10.1124/pr.117.014878.

59. Nowak-Machen, M.; Schmelzle, M.; Hanidziar, D.; Junger, W.; Exley, M.; Otterbein, L.; Wu, Y.; Csizmadia, E.; Doherty, G.; Sitkovsky, M.; Robson, S.C. Pulmonary natural killer T cells play an essential role in mediating hyperoxic acute lung injury. Am J Respir Cell Mol Biol 2013, 48, 601-9. doi: 10.1165/rcmb.2012-0180OC.

60. Han, S.; Mallampalli, R.K. The Role of Surfactant in Lung Disease and Host Defense against Pulmonary Infections. Ann Am Thorac Soc 2015, 12(5):765-74. doi: 10.1513/AnnalsATS.201411-507FR.

61. Marks, L.R.; Davidson, B.A.; Knight, P.R.; Hakansson, A.P. Interkingdom signaling induces Streptococcus pneumoniae biofilm dispersion and transition from asymptomatic colonization to disease. mBio 2013, 4, e00438-13. doi: 10.1128/mBio.00438-13.

62. Reutershan, J.; Vollmer, I.; Stark, S.; Wagner, R.; Ngamsri, K.C.; Eltzschig, H.K. Adenosine and inflammation: CD39 and CD73 are critical mediators in LPS-induced PMN trafficking into the lungs. FASEB J 2009, 23, 473-82. doi: 10.1096/fj.08-119701.

63. Sharma, A.K.; Linden, J.; Kron, I.L.; Laubach, V.E. Protection from pulmonary ischemiareperfusion injury by adenosine A2A receptor activation. Respir Res 2009,10, 58. doi: 10.1186/1465-9921-10-58.

64. Gonzales, J.N.; Gorshkov, B.; Varn, M.N.; Zemskova, M.A.; Zemskov, E.A.; Sridhar, S.; Lucas, R.; Verin, A.D. Protective effect of adenosine receptors against lipopolysaccharideinduced acute lung injury. Am J Physiol Lung Cell Mol Physiol 2014, 306, L497-507. doi: 10.1152/ajplung.00086.2013.

65. He, X.; Hu, J.L.; Li, J.; Zhao, L.; Zhang, Y.; Zeng, Y.J.; Dai, S.S.; He, F.T. A feedback loop in PPAR $\gamma$-adenosine A2A receptor signaling inhibits inflammation and attenuates lung damages in a mouse model of LPS-induced acute lung injury. Cell Signal 2013, 25, 1913-23. doi: 10.1016/j.cellsig.2013.05.024. 
66. Friebe, D.; Yang, T.; Schmidt, T.; Borg, N.; Steckel, B.; Ding, Z.; Schrader, J. Purinergic signaling on leukocytes infiltrating the LPS-injured lung. PLoS One 2014, 9, e95382. doi: 10.1371/journal.pone.0095382. Erratum in: PLoS One 2014, 9, e106356.

67. Hoegl, S.; Brodsky, K.S.; Blackburn, M.R.; Karmouty-Quintana, H.; Zwissler, B.; Eltzschig, H.K. Alveolar Epithelial A2B Adenosine Receptors in Pulmonary Protection during Acute Lung Injury. J Immunol 2015, 195, 1815-24. doi: 10.4049/jimmunol.1401957.

68. Koscsó, B.; Trepakov, A.; Csóka, B.; Németh, Z.H.; Pacher, P.; Eltzschig, H.K.; Haskó, G. Stimulation of $\mathrm{A} 2 \mathrm{~B}$ adenosine receptors protects against trauma-hemorrhagic shockinduced lung injury. Purinergic Signal 2013, 9, 427-32. doi: 10.1007/s11302-013-9362-7.

69. Chen, H.; Yang, D.; Carroll, S.H.; Eltzschig, H.K.; Ravid, K. Activation of the macrophage $\mathrm{A} 2 \mathrm{~b}$ adenosine receptor regulates tumor necrosis factor-alpha levels following vascular injury. Exp Hematol 2009, 37, 533-8. doi: 10.1016/j.exphem.2009.02.001.

70. Nie, W.; Zhang, Y.; Jee, S.H.; Jung, K.J.; Li, B.; Xiu, Q. Obesity survival paradox in pneumonia: a meta-analysis. BMC Med 2014, 12, 61. doi: 10.1186/1741-7015-12-61.

71. Stefan, N.; Birkenfeld, A.L.; Schulze, M.B.; Ludwig, D.S. Obesity and impaired metabolic health in patients with COVID-19. Nat Rev Endocrinol 2020, 16, 341-342. doi: 10.1038/s41574-020-0364-6.

72. Dietz, W.; Santos-Burgoa, C. Obesity and its Implications for COVID-19 Mortality. Obesity (Silver Spring) 2020, 28, 1005. doi: 10.1002/oby.22818.

73. Simonnet, A.; Chetboun, M.; Poissy, J.; Raverdy, V.; Noulette, J.; Duhamel, A.; Labreuche, J.; Mathieu, D.; Pattou, F.; Jourdain, M.; LICORN and the Lille COVID-19 and Obesity study group. High Prevalence of Obesity in Severe Acute Respiratory Syndrome Coronavirus-2 (SARS-CoV-2) Requiring Invasive Mechanical Ventilation. Obesity (Silver Spring) 2020, 28, 1195-1199. doi: 10.1002/oby.22831.

74. Richardson, S.; Hirsch, J.S.; Narasimhan, M.; Crawford, J.M.; McGinn, T.; Davidson, K.W.; and the Northwell COVID-19 Research Consortium; Barnaby, D.P.; Becker, L.B.; Chelico, J.D.; Cohen, S.L.; Cookingham, J.; Coppa, K.; Diefenbach, M.A.; Dominello, A.J.; DuerHefele, J.; Falzon, L.; Gitlin, J.; Hajizadeh, N.; Harvin, T.G.; Hirschwerk, D.A.; Kim, E.J.; Kozel, Z.M.; Marrast, L.M.; Mogavero, J.N.; Osorio, G.A.; Qiu, M.; Zanos, T.P. Presenting Characteristics, Comorbidities, and Outcomes Among 5700 Patients Hospitalized With COVID-19 in the New York City Area. JAMA 2020, 323, 2052-9. doi: 10.1001/jama.2020.6775. Erratum in: doi: 10.1001/jama.2020.7681.

75. Finer, N.; Garnett, S.P.; Bruun, J.M. COVID-19 and obesity. Clin Obes 2020, 10, e12365. doi: 10.1111/cob.12365.

76. Buscemi, S.; Buscemi, C.; Batsis, J.A. There is a relationship between obesity and COVID19 but more information is needed. Obesity (Silver Spring) 2020, 10.1002/oby.22883. doi: 10.1002/oby.22883.

77. Balkau, B.; Valensi, P.; Eschwege, E.; Slama, G. A review of the metabolic syndrome. Diabetes Metab 2007, 33, 405e13. https://doi.org/10.1016/ j.diabet.2007.08.001.

78. Hanff, T.C.; Harhay, M.O.; Brown, T.S.; Cohen, J.B.; Mohareb, A.M. Is There an Association Between COVID-19 Mortality and the Renin-Angiotensin System-a Call for Epidemiologic Investigations. Clin Infect Dis 2020, ciaa329. doi: 10.1093/cid/ciaa329. 
79. de Lucena, T.M.C.; da Silva Santos, A.F.; de Lima, B.R.; de Albuquerque Borborema, M.E.; de Azevêdo Silva, J. Mechanism of inflammatory response in associated comorbidities in COVID-19. Diabetes Metab Syndr 2020, 14, 597-600. doi: 10.1016/j.dsx.2020.05.025.

80. Fang, L.; Karakiulakis, G.; Roth, M. Are patients with hypertension and diabetes mellitus at increased risk for COVID-19 infection? Lancet Respir Med 2020, 8, e21. doi: 10.1016/S2213-2600(20)30116-8. Erratum in: Lancet Respir Med 2020, 8, e54.

81. Meng, J.; Xiao, G.; Zhang, J.; He, X.; Ou, M.; Bi, J.; Yang, R.; Di, W.; Wang, Z.; Li, Z.; Gao, H.; Liu, L.; Zhang, G. Renin-angiotensin system inhibitors improve the clinical outcomes of COVID-19 patients with hypertension. Emerg Microbes Infect 2020, 9, 757-760. doi: 10.1080/22221751.2020.1746200.

82. Bloomgarden, Z.T. Diabetes and COVID-19. J Diabetes 2020, 12, 347-348. doi: 10.1111/17530407.13027.

83. Brufsky, A. Hyperglycemia, hydroxychloroquine, and the COVID-19 pandemic. J Med Virol 2020, 92, 770-775. doi: 10.1002/jmv.25887.

84. Zhao, L. Obesity accompanying COVID-19: the role of epicardial fat. Obesity (Silver Spring) 2020. doi: 10.1002/oby.22867.

85. Singh, A.K.; Gupta, R.; Ghosh, A.; Misra, A. Diabetes in COVID-19: Prevalence, pathophysiology, prognosis and practical considerations. Diabetes Metab Syndr 2020, 14, 303-310. doi: 10.1016/j.dsx.2020.04.004.

86. Zhang C, Wu Z, Li JW, Zhao H, Wang GQ. Cytokine release syndrome in severe COVID19: interleukin-6 receptor antagonist tocilizumab may be the key to reduce mortality. Int J Antimicrob Agents. 2020;55(5):105954. doi:10.1016/j.ijantimicag.2020.105954

87. Zhang, W.; Zhao, Y.; Zhang, F.; Wang, Q.; Li, T.; Liu, Z.; Wang, J.; Qin, Y.; Zhang, X.; Yan, $X . ; Z$ Zng, $X . ; Z$ Zhang, $S$. The use of anti-inflammatory drugs in the treatment of people with severe coronavirus disease 2019 (COVID-19): The Perspectives of clinical immunologists from China. Clin Immunol 2020, 214, 108393. doi: 10.1016/j.clim.2020.108393.

88. Fu, B.; Xu, X.; Wei, H. Why tocilizumab could be an effective treatment for severe COVID19? J Transl Med 2020, 18, 164. doi: 10.1186/s12967-020-02339-3.

89. Lu, C.C.; Chen, M.Y.; Lee, W.S.; Chang, Y.L. Potential therapeutic agents against COVID19: What we know so far. I Chin Med Assoc 2020, 83, 534-536. doi: 10.1097/JCMA.0000000000000318.

90. Misra, D.P.; Agarwal, V.; Gasparyan, A.Y.; Zimba, O. Rheumatologists' perspective on coronavirus disease 19 (COVID-19) and potential therapeutic targets. Clin Rheumatol 2020, 39, 2055-2062. doi: 10.1007/s10067-020-05073-9.

91. Toniati, P.; Piva, S.; Cattalini, M.; Garrafa, E.; Regola, F.; Castelli, F.; Franceschini F.; Airò, P.; Bazzani, C.; Beindorf, E.A.; Berlendis, M.; Bezzi, M.; Bossini, N.; Castellano, M.; Cattaneo, S.; Cavazzana, I.; Contessi, G.B.; Crippa, M.; Delbarba, A.; De Peri, E.; Faletti, A.; Filippini, M.; Filippini, M.; Frassi, M.; Gaggiotti, M.; Gorla, R.; Lanspa, M.; Lorenzotti, S.; Marino, R.; Maroldi, R.; Metra, M.; Matteelli, A.; Modina, D.; Moioli, G.; Montani, G.; Muiesan, M.L.; Odolini, S.; Peli, E.; Pesenti, S.; Pezzoli, M.C.; Pirola, I.; Pozzi, A.; Proto, A.; Rasulo, F.A.; Renisi, G.; Ricci, C.; Rizzoni, D.; Romanelli, G.; Rossi, M.; Salvetti, M.; Scolari, F.; Signorini, L.; Taglietti, M.; Tomasoni, G.; Tomasoni, L.R.; Turla, F.; Valsecchi, A.; Zani, D.; Zuccalà, F.; Zunica, F.; Focà, E.; Andreoli, L.; Latronico, N. Tocilizumab for the 
treatment of severe COVID-19 pneumonia with hyperinflammatory syndrome and acute respiratory failure: A single center study of 100 patients in Brescia, Italy. Autoimmun Rev 2020, 19, 102568. doi: 10.1016/j.autrev.2020.102568.

92. Sciascia, S.; Aprà, F.; Baffa, A.; Baldovino, S.; Boaro, D.; Boero, R.; Bonora, S.; Calcagno, A.; Cecchi, I.; Cinnirella, G.; Converso, M.; Cozzi, M.; Crosasso, P.; De Iaco, F.; Di Perri, G.; Eandi, M.; Fenoglio, R.; Giusti, M.; Imperiale, D.; Imperiale, G.; Livigni, S.; Manno, E.; Massara, C.; Milone, V.; Natale, G.; Navarra, M.; Oddone, V.; Osella, S.; Piccioni, P.; Radin, M.; Roccatello, D.; Rossi, D. Pilot prospective open, single-arm multicentre study on offlabel use of tocilizumab in patients with severe COVID-19. Clin Exp Rheumatol 2020, 38, 529-532.

93. Colaneri, M.; Bogliolo, L.; Valsecchi, P.; Sacchi, P.; Zuccaro, V.; Brandolino, F.; Montecucco, C.; Mojoli, F.; Giusti, E.M.; Bruno, R. The Covid Irccs San Matteo Pavia Task Force. Tocilizumab for Treatment of Severe COVID-19 Patients: Preliminary Results from SMAtteo COvid19 REgistry (SMACORE). Microorganisms 2020, 8, 695 . doi: 10.3390/microorganisms8050695.

94. Capra, R.; De Rossi, N.; Mattioli, F.; Romanelli, G.; Scarpazza, C.; Sormani, M.P.; Cossi, S. Impact of low dose tocilizumab on mortality rate in patients with COVID-19 related pneumonia. Eur J Intern Med 2020, 76, 31-35. doi: 10.1016/j.ejim.2020.05.009.

95. Klopfenstein, T.; Zayet, S.; Lohse, A.; Balblanc, J.C.; Badie, J.; Royer, P.Y.; Toko, L.; Mezher, C.; Kadiane-Oussou, N.J.; Bossert, M.; Bozgan, A.M.; Charpentier, A.; Roux, M.F.; Contreras, R.; Mazurier, I.; Dussert, P.; Gendrin, V.; Conrozier, T.; HNF Hospital Tocilizumab multidisciplinary team. Tocilizumab therapy reduced intensive care unit admissions and/or mortality in COVID-19 patients. Med Mal Infect 2020, S0399077X(20)30129-3. doi: 10.1016/j.medmal.2020.05.001.

96. Luo, P.; Liu, Y.; Qiu, L.; Liu, X.; Liu, D.; Li, J. Tocilizumab treatment in COVID-19: A single center experience. J Med Virol 2020, 92, 814-818. doi: 10.1002/jmv.25801.

97. Xu, X.; Han, M.; Li, T.; Sun, W.; Wang, D.; Fu, B.; Zhou, Y.; Zheng, X.; Yang, Y.; Li, X.; Zhang, X.; Pan, A.; Wei, H. Effective treatment of severe COVID-19 patients with tocilizumab. Proc Natl Acad Sci U S A 2020, 117, 10970-10975. doi: 10.1073/pnas.2005615117.

98. Zhang, X.; Song, K.; Tong, F.; Fei, M.; Guo, H.; Lu, Z.; Wang, J.; Zheng, C. First case of COVID-19 in a patient with multiple myeloma successfully treated with tocilizumab. Blood Adv 2020, 4, 1307-1310. doi: 10.1182/bloodadvances.2020001907.

99. Mihai, C.; Dobrota, R.; Schröder, M.; Garaiman, A.; Jordan, S.; Becker, M.O.; Maurer, B.; Distler, O. COVID-19 in a patient with systemic sclerosis treated with tocilizumab for SScILD. Ann Rheum Dis 2020, 79, 668-669. doi: 10.1136/annrheumdis-2020-217442.

100. Fontana, F.; Alfano, G.; Mori, G.; Amurri, A.; Tei, L.; Ballestri, M.; Leonelli, M.; Facchini, F.; Damiano, F.; Magistroni, R.; Cappelli, G. COVID-19 pneumonia in a kidney transplant recipient successfully treated with tocilizumab and hydroxychloroquine. Am J Transplant 2020, 20, 1902-1906. doi: 10.1111/ajt.15935.

101. van Kraaij,T.D.; Mostard, R.L.; Ramiro, S.; Magro Checa, C.; van Dongen, C.M.; van Haren, E.H.; Buijs, J.; Landewé, R.B. Tocilizumab in Severe COVID-19 Pneumonia and Concomitant Cytokine Release Syndrome. Eur J Case Rep Intern Med 2020, 7, 001675. doi: 10.12890/2020_001675. 
102. Radbel, J.; Narayanan, N.; Bhatt, P.J. Use of Tocilizumab for COVID-19-Induced Cytokine Release Syndrome: A Cautionary Case Report. Chest 2020, 158, e15-e19. doi: 10.1016/j.chest.2020.04.024.

103. Morrison, A.R.; Johnson, J.M.; Ramesh, M.; Bradley, P.; Jennings, J.; Smith, Z.R. Acute hypertriglyceridemia in patients with COVID-19 receiving tocilizumab. J Med Virol 2020, 10.1002/jmv.25907. doi: 10.1002/jmv.25907.

104. Bennardo, F.; Buffone, C.; Giudice, A. New therapeutic opportunities for COVID-19 patients with Tocilizumab: Possible correlation of interleukin-6 receptor inhibitors with osteonecrosis of the jaws. Oral Oncol 2020, 106, 104659. doi:10.1016/j.oraloncology.2020.104659.

105. Vikse J, Henry BM. Tocilizumab in COVID-19: Beware the risk of intestinal perforation [published online ahead of print, 2020 May 7]. Int J Antimicrob Agents. 2020;106009. doi:10.1016/j.ijantimicag.2020.106009.

106. Aggarwal, N.R.; D'Alessio, F.R.; Eto, Y.; Chau, E.; Avalos, C.; Waickman, A.T.; Garibaldi, B.T.; Mock, J.R.; Files, D.C.; Sidhaye, V.; Polotsky, V.Y.; Powell, J.; Horton, M.; King, L.S. Macrophage A2A adenosinergic receptor modulates oxygen-induced augmentation of murine lung injury. Am J Respir Cell Mol Biol 2013, 48, 635-46. doi: 10.1165/rcmb.20120351OC.

107. Jacobson, K.A.; Tosh, D.K.; Jain, S.; Gao, Z.G. Historical and Current Adenosine Receptor Agonists in Preclinical and Clinical Development. Front Cell Neurosci 2019, 13, 124. doi: 10.3389/fncel.2019.00124.

108. Spicuzza, L.; Di Maria, G.; Polosa, R. Adenosine in the airways: implications and applications. Eur J Pharmacol 2006, 533, 77-88. doi: 10.1016/j.ejphar.2005.12.056.

109. Holgate, S.T.; Cushley, M.J.; Mann, J.S.; Hughes, P.; Church, M.K. The action of purines on human airways. Arch Int Pharmacodyn Ther 1986, 280, 240-52.

110. Cushley, M.J.; Tattersfield, A.E.; Holgate, S.T. Inhaled adenosine and guanosine on airway resistance in normal and asthmatic subjects. 1983. Br J Clin Pharmacol 2004, 58, S751-5; discussion S756-8. doi: 10.1111/j.1365-2125.2004.02285.x.

111. van der Wiel, E.; Lexmond, A.J.; van den Berge, M.; Postma, D.S.; Hagedoorn, P.; Frijlink, H.W.; Farenhorst, M.P.; de Boer, A.H.; Ten Hacken, N.H.T. Targeting the small airways with dry powder adenosine: a challenging concept. Eur Clin Respir J 2017, 4, 1369328. doi: 10.1080/20018525.2017.1369328.

112. Belanger, M.J.; Hill, M.A.; Angelidi, A.M.; Dalamaga, M.; Sowers, J.R.; Mantzoros, C.S. Covid-19 and Disparities in Nutrition and Obesity. $N$ Engl J Med 2020. doi: 10.1056/NEJMp2021264

113. Di Renzo, L.; Gualtieri, P.; Pivari, F.; Soldati, L.; Attinà, A.; Cinelli, G.; Leggeri, C.; Caparello, G.; Barrea, L.; Scerbo, F.; Esposito, E.; De Lorenzo, A. Eating habits and lifestyle changes during COVID-19 lockdown: an Italian survey. Version 2. J Transl Med 2020, 18, 229. doi: 10.1186/s12967-020-02399-5.

114. Romano, L.; Bilotta, F.; Dauri, M.; Macheda, S.; Pujia, A.; De Santis, G.L.; Tarsitano, M.G.; Merra, G.; Di Renzo, L.; Esposito, E.; De Lorenzo, A. Short Report - Medical nutrition therapy for critically ill patients with COVID-19. Eur Rev Med Pharmacol Sci 2020 24, 40354039. doi: 10.26355/eurrev_202004_20874. 
115. Gualtieri, P.; Falcone, C.; Romano, L.; Macheda, S.; Correale, P.; Arciello, P.; Polimeni, N.; Lorenzo, A. Body Composition Findings by Computed Tomography in SARS-CoV-2 Patients: Increased Risk of Muscle Wasting in Obesity. Int J Mol Sci 2020, 21, E4670. doi: 10.3390/ijms21134670. 